\title{
Transplantation of olfactory ensheathing cells in spinal cord injury
}

\author{
Johana Tello Velasquez ${ }^{1}$, Jenny A. K. Ekberg ${ }^{1,2}$, James A. St John ${ }^{1}$
}

${ }^{1}$ Eskitis Institute for Drug Discovery, Griffith University, Brisbane, Australia

${ }^{2}$ School of Biomedical Sciences, Queensland University of Technology, Brisbane, Australia

Corresponding author:

James St John (family name = St John)

j.stjohn@griffith.edu.au,

phone: +61-7-3735 3660

fax: +61-7-3735 4255 


\begin{abstract}
Spinal cord injury is characterized by massive cellular and axonal loss, a neurotoxic environment, inhibitory molecules and physical barriers that hamper nerve regeneration and reconnection leading to chronic paralysis. Transplantation of different types of cells is one of the strategies being examined in order to restore the lost cell populations and to re-establish a permissive environment for nerve regeneration. The mammalian olfactory system is one of the few zones in the body where neurogenesis occurs during the lifetime of the organism, with olfactory neurons being replaced daily with their axons elongating from the peripheral nervous system into the central nervous system to re-establish functional connections. The regenerative ability of this system is largely attributed to the presence of a unique group of cells called olfactory ensheathing cells (OECs). OECs have emerged as an encouraging cell candidate for transplantation therapies to repair the injured spinal cord with multiple animal models showing significant functional improvements and several human trials establishing that the procedure is safe and feasible. Even though the results are promising with some animal models showing remarkable restoration of function, the variability amongst studies in terms of outcome assessments, cell purity, cell culture and transplantation protocols make it difficult to reach firm conclusions about the effectiveness of OEC transplant therapy to treat the injured spinal cord. These variations need to be addressed in order to achieve a more realistic understanding of how the benefits of OEC transplantation enhance the therapeutic outcomes.
\end{abstract}




\section{Abbreviations}

$\mathrm{BDNF}=$ brain-derived neurotrophic factor

cAMP = cyclic adenosine monophosphate

CNS $=$ central nervous system

$\mathrm{CP}=$ cribriform plate

$\mathrm{CSPG}=$ chondroitin sulfate proteoglycan

DAPI = 4',6-diamidino-2-phenylindole

dBcAMP = dibutyryl cyclic adenosine

monophosphate

FGF $=$ fibroblast growth factor

GDNF = glial cell-derived neurotrophic factor

GFAP = glial fibrillary acidic protein

$\mathrm{GL}=$ glomerular layer

HNK-1 = human natural killer-1

IGF = insulin-like growth factor

$\mathrm{LP}=$ lamina propria

MAG = myelin associated glycoprotein

$\mathrm{NFL}=$ nerve fibre layer

NGF $=$ nerve growth factor

Nogo $=$ neurite outgrowth inhibitory protein

NPY = neuropeptide $\mathrm{Y}$

NT4 = neurotrophin 4

NT5 = neurotrophin 5

$\mathrm{OE}=$ olfactory epithelium

OEC = olfactory ensheathing cell

OMgp = oligodendrocyte-myelin

glycoprotein p75 ${ }^{\mathrm{NTR}}=$ p75 low-affinity neurotrophin receptor

PNS = peripheral nervous system

SCI = spinal cord injury

TROY $=$ TNFRSF expressed on the mouse embryo

VEGF = vascular endothelial growth factor 


\section{Table of contents}

1. Spinal cord injury

2. Endogenous glial cells and their role in spinal cord injury

3. The mammalian olfactory nervous system

3.1. Olfactory ensheathing cells - the glia of the olfactory system

3.2. Differences between olfactory ensheathing cells and Schwann cells

4. Use of glial cells in the treatment of spinal cord injuries

4.1. Transplanted OECs in spinal injury models

4.2. Human trials of OEC transplantation into the injured spinal cord

4.3. OECs are a heterogeneous population - which source should be used?

4.4. Purification of OECs and contaminating cells

5. Limitations of the use of OECs

6. Future outlook and opportunities

7. References 


\section{Spinal cord injury}

Spinal cord injury results in large-scale neuronal loss with very limited capacity for regeneration, leading to chronic paralysis. The main factor hampering recovery is the inability of regenerating spinal cord axons to reach their target (reviewed by Leal-Filho, 2011). The pathophysiology of spinal cord injury is divided in two stages: the primary and secondary lesion. The primary lesion is caused by the direct mechanical trauma, i.e., laceration, contusion or compression, resulting in structural disturbances, death of neurons and damage to neural connections. This is followed by ischemia and microvascular damage (Beattie et al., 1997), as well as excessive extracellular glutamate as a consequence of neuronal cell death (Hermann et al., 2001). The high concentration of glutamate and other excitatory amino acids lead to further progressive cell death via excitotoxicity and free radical production (Byrnes et al., 2009). Altogether, the cell death, oxidative stress and inflammatory responses result in massive neuronal and glial cell death (Hulsebosch, 2002; Jones et al., 2003; Kingman 2009).

The secondary lesion is characterized by continued inflammatory immune responses, including cytokine and interleukin secretion by macrophages and neutrophils (Bolton, 2005). Furthermore, axon demyelination, as a consequence of oligodendrocyte cell death, results in loss of axonal conduction and subsequently a loss in synaptic communication. Activated astrocytes migrate to the injury site to degrade axonal debris and remove toxic chemicals, but the vast network of activated astrocytes creates a glial scar; a compact structure that becomes a barrier preventing regenerating axons from reaching their target (Bunge et al., 1960; Matthews et al., 1979). Thus, the complex damage resulting from the initial nerve injury leads to an environment that hampers or even completely inhibits neuronal regeneration (Figure 1) (Hulsebosch, 2002; Kingman 2009; LealFilho, 2011). 
Current therapies for spinal cord injury do not lead to significant neural regeneration and functional recovery. Most of these therapies have aimed to minimize the post-traumatic cell damage but fail to achieve the re-establishment of neuronal connections. Drug therapy is generally applied immediately following trauma to treat inflammation and initial degeneration (reviewed by Stahel et al., 2012; Batzofin et al., 2013; Hurlbert et al., 2013). This treatment is often followed by long term therapies aimed at promoting axonal growth and neutralising the toxic environment at the injury site. A major factor hampering axonal regeneration following spinal cord injury is the downregulation of endogenous neurotrophins and one method that has shown promise is the injection of neurotrophins at the site of injury to replace the lost endogenous neurotrophins (Hulsebosch, 2002). Peripheral glial cells can produce many growth factors and hence transplanting glia to the injury site is an even more promising approach as these cells can integrate with endogenous cells and scar tissue, producing a more long-term growth-promoting environment (Yan et al., 2001; Feron et al., 2005; Cao et al., 2007; Centenaro et al., 2011). Similarly, pluripotent stem cells can be transplanted to the injury site, potentially resulting in neuronal regeneration and production of glial cells. This method is still experimental, but has resulted in promising functional outcomes in animals (reviewed by Antonic et al., 2013). Further, manipulation of gene expression to block production of growth-inhibitory and toxic molecules has also resulted in some promising functional outcomes (reviewed by Leal-Filho, 2011). Overall, however, while these therapeutic interventions have led to some positive outcomes, to date, none have produced a significant functional recovery in humans (Lim and Tow, 2007; Leal-Filho, 2011).

\section{Endogenous glial cells and their role in spinal cord injury}

Glial cells are the most abundant cells in the nervous system. They are closely associated with neurons and were previously described simply as supportive nervous tissue. A deeper understanding 
of glial cell biology, however, has demonstrated that glial cells exhibit a multitude of complex roles and are essential for the development and function of the entire nervous system (Jessen, 2006). Glial cells are a heterogeneous population of cells that differ in developmental origin, molecular composition, structure and specific behaviour, and exist together with neurons and other cells in an integrated and co-dependent system (Chung and Barres, 2011). Throughout the nervous system, glial cells have crucial roles in axonal extension and guidance, protection against mechanical, chemical and oxidative injury, as well as preservation of the electrical and chemical balance of all neurons (Ndubaku and de Bellard, 2008).

Glial cells can be broadly classified as being either central nervous system glia or peripheral nervous system glia. In the mature central nervous system (CNS), there are two major types of glial cells of neural origin; astrocytes and oligodendrocytes. Other types of CNS glial cells exist that originate from non-neuronal precursors; microglia constitute part of the innate immune system and originate from macrophage lineages (Chugani et al., 1991). In the peripheral nervous system (PNS), Schwann cells constitute the main glial cell type, with the exception of the olfactory nervous system, which is populated by specialized glia termed olfactory ensheathing cells (OECs).

Astrocytes play a critical role in the function and homeostasis of the CNS. They are required for the formation and maintenance of the blood-brain barrier, provide support for axonal extension and play an active role in neuronal signalling by exchange of ions and production of neurotransmitters, as well as cell adhesion and synapse signalling molecules (Kriegstein and Gotz, 2003). Astrocyteneuron interactions are known to secure the survival and normal function of neurons (Jessen, 2004). Numerous studies have demonstrated that astrocytes play important neuroprotective roles, in neurodegenerative disorders (reviewed by Singh et al., 2011; Cabezas et al., 2012) and they have 
the ability to promote neuronal survival by protecting against reactive oxygen species and other stressors (Lopez et al., 2007).

After spinal cord injury, astrocytes respond rapidly by migrating to the injury site, where they proliferate and form a compact structure, a glial scar, to preserve the blood-brain barrier, protecting the CNS and maintaining the adequate ionic environment necessary for nerve function. However, the glial scar eventually becomes a physical barrier that stops damaged axons from regenerating and reconnecting (Figure 1) (Leal-Filho, 2011). Furthermore, astrocytes respond to neuronal injury by increasing their proliferation and by secreting glycoproteins such as chondroitin sulfate proteoglycans (CSPG), which act to inhibit axon elongation (Table 1) (Qiu et al., 2002; Su et al., 2009).

Oligodendrocytes are morphologically similar to astrocytes, albeit with fewer and smaller branched processes. They play different roles in the modulation of neuronal function as well as the regulation of proliferation, survival and differentiation of neurons (Jauregui-Huerta et al., 2010) The most important role of oligodendrocytes, however, is to myelinate axons. The myelin sheet provides electrical insulation around the nerve fibres, speeding the transmission of electrical signals (Jessen, 2004). The myelin layer also protects the axons by creating a "safe chamber", resembling a growthpromoting channel through which the axon extends. After spinal cord injury, populations of oligodendrocytes are rapidly affected by high levels of glutamate and massive cell death follows. Oligodendrocytes that do survive produce neurite outgrowth inhibitor (Nogo), myelin-associated glycoprotein (MAG), and oligodendrocyte-myelin glycoprotein (OMgp) (Table 1), proteins that bind to the Nogo receptor, repressing myelin production and affecting axonal outgrowth and neuronal synapses (Jones et al., 2003). Microglia, which are essentially macrophages present within 
the CNS, respond to injury by migrating to the injury site, where they phagocytose debris, secrete a range of both pro- and anti-inflammatory cytokines and growth factors which initially have a neuroprotective effect. Over time, however, microglia near and in the injury site respond to the constant prolonged activation by secreting molecules that are growth-inhibitory or toxic, thus repressing axonal regeneration (Chatzipanteli et al., 2002; Pearse et al., 2003; Block and Hong, 2005). The majority of the activated microglia transition to the M1 type, which can directly induce neuronal death (Kigerl et al., 2009; Gao et al., 2013). Thus, together with the glial scar, the local environment at a CNS injury site inhibits long-term neuronal extension and regeneration.

The PNS differs dramatically from the CNS in terms of capability to regenerate itself after injury. In contrast to central nerves, peripheral neurons in general regenerate after injury, unless large nerves have been completely severed. Schwann cells play an active role in repair of peripheral damaged nerves as a consequence of their ability to differentiate, migrate, proliferate, secrete growth factors, and produce myelin. Schwann cells are classified as either myelinating or non-myelinating. Myelinating Schwann cells enwrap individual peripheral axons, forming the myelin sheath, whereas the non-myelinating type have metabolic and mechanical support functions (Jessen, 2004). After spinal cord injury, Schwann cells migrate from the periphery into the injury site within in the CNS, and participate in endogenous repair processes (Table 1). They re-enter the cell cycle, lose their myelinating phenotype and de-differentiate into an immature state, and begin to express trophic factors and cell adhesion molecules that provide a more favourable environment for axon regeneration and extension (Oudega and $\mathrm{Xu}, 2006)$.

One approach to improve the outcomes after spinal cord injury is to transplant glial cells into the injury site to reduce inflammation, and which will help form a glial bridge across the injury site and thereby promote axon extension. The glial of the PNS system, Schwann cells and OECs, have been 
trialled in animal models and in humans with various outcomes. The OECs have unique characteristics that may confer an advantage over other glial cell types for transplant therapies.

\section{The mammalian olfactory nervous system}

The mammalian olfactory nervous system is one of the few regions in the CNS in which neurogenesis continuously occurs during the lifetime of the organism (Mackay-Sim and Kittel, 1991a; Mackay-Sim and Kittel, 1991b). The primary sensory neurons of the olfactory system line the dorsal/caudal nasal epithelium and are directly exposed to the environment (Figure 2). The neurons are subjected to attack and destruction by bacterial (St John et al., 2014) and viral pathogens as well as toxins within the air and thus need to be replaced throughout life. Whilst the average life-span of olfactory neurons has not been clearly determined in humans, mouse olfactory neurons generally live for one to three months. Neurons that degenerate are rapidly replaced by new neurons arising from progenitor cells that line in the basal layer of the olfactory mucosa (MackaySim and Kittel, 1991b), a process that occurs throughout life (Ramon-Cueto and Santos-Benito, 2001) .

The primary olfactory system comprises the olfactory mucosa and the bundles of olfactory nerves that project into the olfactory bulb. Stem cells that line basal layer of the olfactory epithelium give rise to the primary olfactory sensory neurons which migrate apically to populate the olfactory epithelium (Figure 2). Olfactory sensory neurons have a bipolar morphology with a single dendrite extending onto the surface of the epithelium and a single axon projecting to and terminating in the olfactory bulb. Each olfactory neuron expresses a single odorant receptor type with the neurons mosaically distributed throughout the epithelium, but the axons of the same odorant receptor type converge to the same targets within the olfactory bulb (Vassar et al., 1994; Mombaerts et al., 1996). To reach their targets in the olfactory bulb, the axons of the olfactory sensory neurons project 
through the lamina propria that underlies the olfactory epithelium and pass through the bony cribriform plate to enter the nerve fibre layer which is the outer layer of the olfactory bulb and within the CNS. Thus, new axons must constantly traverse the PNS-CNS border and find their correct targets inside the olfactory bulb (Valverde et al., 1992; Tennent and Chuah, 1996; Chehrehasa et al., 2010). The constant ability of olfactory neurons to regenerate and the unique ability of olfactory axons to extend across the PNS-CNS boundary are attributed to the presence of the glia of the olfactory system, called OECs.

\subsection{Olfactory ensheathing cells - the glia of the olfactory system}

OECs arise from neural crest (Barraud et al., 2010) and they are constantly in close contact with the axons of olfactory neurons all the way from the nasal epithelium to the outer layer of the olfactory bulb. OECs ensheathe the axons of olfactory neurons by the extension of cytoplasmic processes (Chuah and Zheng, 1992; Tennent and Chuah, 1996) followed by the fasciculation of the axons into larger bundles which ultimately join to form the olfactory nerve (Whitesides and LaMantia, 1996). In contrast to Schwann cells, which in the process of myelination enwrap one single axon (Figure 3), OECs ensheathe bundles of multiple axons by projecting extensive thin cytoplasmic processes around and between the numerous axons within the fascicles (Figure 2, Figure 3).

OECs also have a role in promoting axon growth and are known to secrete numerous axon growth promoting factors, such as nerve growth factor, brain derived neurotrophic factor and neuregulins (Boruch et al., 2001). During development, OECs proliferate and migrate ahead of axons or surround the growth cones of axons (Tennent and Chuah, 1996; Chehrehasa et al., 2010). Loss of OECs from the olfactory nerve during development results in poor axon growth and targeting (Barraud et al., 2013) which demonstrates that OECs are crucial to the growth and maintenance of axons. 
OECs are also thought to be crucial for regeneration during normal turnover of olfactory sensory neurons or after large-scale infection by bacteria and viruses, or major injury. Bacterial infection can lead to the death of olfactory sensory neurons and subsequently their axons (Figure 2; St John et al., 2014), or injury can directly lead to the destruction of the axons (Graziadei et al., 1978; Chehrehasa et al., 2010). The debris from the degenerated axons must be removed but unlike other areas of the body where cells of the immune system usually clear away debris, in the olfactory system this function primarily relies on the OECs (Su et al., 2013). OECs have been shown to continuously phagocytose debris arising from the degenerating axons that occurs during normal turnover of neurons or after widespread injury (Wewetzer et al., 2005; Su et al., 2013). OECs are also able to phagocytose bacteria and thereby protect the olfactory pathway from infection (Wewetzer et al., 2005; Leung et al., 2008; Panni et al., 2013).

OECs form a three-dimensional structure resembling a tunnel through which the axons extend (Figure 3; Li et al., 2005). These structures remain intact even after olfactory axons have degenerated completely following large-scale injury to the olfactory epithelium (Li et al., 2005). However, after large scale injury, OECs can proliferate not only locally around the injury but also from precursors that are present in the olfactory mucosa after which they then migrate along the olfactory nerve (Chehrehasa et al., 2012). By maintaining open channels through which regenerating axons can extend and by responding to injury by proliferating and migrating to the region of need, the OECs with their axon growth-promoting properties provide the structure and support needed for the continuous successful regeneration of the olfactory system.

OECs produce numerous growth factors such as fibroblast growth factor (FGF), insulin-like growth factor (IGF), vascular endothelial growth factor (VEGF), as well as neurotrophic factors such as 
nerve growth factor (NGF), brain-derived neurotrophic factor (BDNF), glial cell-derived neurotrophic factor (GDNF), neurotrophin 4 (NT4) and NT5; as well as extracellular matrix and cell adhesion molecules including laminin, collagen, galectin-1, heparin sulfate proteoglycans, glialderived nexin and N-cadherin (Doucette, 1990; Doucette and Devon, 1993; Chuah and Teague, 1999; Kafitz and Greer, 1999; Tisay and Key, 1999; Boruch et al., 2001; Woodhall et al., 2001; Woodhall et al., 2003; Chuah et al., 2004; Chung et al., 2004; Vincent et al., 2005b; Mackay-Sim and St John, 2011). These OEC-derived factors are likely to play an important role in nerve repair and regeneration processes as well as neutralization of toxic cell environments due to the excess of free radicals and neurotransmitters such as glutamate (Doucette, 1995; Ramon-Cueto, 2000; Woodhall et al., 2001; Woodhall et al., 2003; Ramon-Cueto, 2011).

\subsection{Differences between olfactory ensheathing cells and Schwann cells}

Originally, OECs were referred to as Schwann cells of the olfactory system (Doucette, 1984), but their distinctive characteristics separated them from other glial cell types to such an extent that they were classified as an individual glial type. OECs possess features of both CNS and PNS glia in terms of morphology and molecular profile, consistent with their location to both the central and peripheral part of the olfactory nervous system and their ability to cross the PNS-CNS interface. Developmentally, OECs and Schwann cells are of neural crest origin (Barraud et al., 2010), in contrast to astrocytes, which arise from radial glia of neuroepithelial origin (Kriegstein and Gotz, 2003). OECs are known to express a number of different proteins found in either Schwann cells or astrocytes. For example non-myelinating Schwann cells and OECs (except those in the inner nerve fibre layer of the olfactory bulb) present immunoreactivity for the p75 low-affinity neurotrophin receptor (p75 ${ }^{\mathrm{NTR}}$ ) (Ramon-Cueto, 2000). 
Whilst similarities between Schwann cells and OECs are evident, one particularly important difference exists in the ability to interact with astrocytes. In contrast to Schwann cells, OECs interact freely with astrocytes, without causing detrimental effect on the astrocyte population (Lakatos et al., 2000). This specific feature is of great interest for nerve regeneration therapies where both populations (OECs and astrocytes) interact at an injury site (Chuah et al., 2011). When OECs are confronted with astrocytes in spinal cord injury sites, astrocyte processes, which form the glial scar, alter their morphology to create a bridging pathway with OECs that allow severed axons to extend across the lesion establishing functional connections (Ramer et al., 2004; Li et al., 2012).

In contrast to Schwann cells, OECs migrate ahead of the regenerating axons, extending their processes to provide a cellular pathway that facilitate axonal extension and adhesion (Tennent and Chuah, 1996; Chehrehasa et al., 2010). OECs increase their migration ability by the formation of bigger and thicker processes (Valverde et al., 1992), maintaining a continuous ensheathment of the axons during the regeneration process and leading to enhanced axon growth (Chehrehasa et al., 2010). The capacity of OECs to promote olfactory system renewal and regeneration, as well as their capacity to bridge, enter, and interact with cells of injured host tissue, constitute key factors contributing to the increasing interest in the use of transplanted OECs as therapeutic candidates in spinal cord injury treatments.

\section{Use of glial cells in the treatment of spinal cord injuries}

Re-establishment of nerve connections after spinal cord injury depends of the ability of axons to extend along a pathway to reach their targets. This living pathway consists of glial cells, which provide a dynamic channel through which axons can extend towards their targets (Ramer et al., 2004; Li et al., 2012). After spinal cord injury, the severed nerves are able to survive and sprout 
locally. However, they are unable to elongate and re-establish the connections, primarily because the glial pathway is altered, blocked and sometimes completely lost. Consequently, a primary objective in the treatment of spinal cord injury is re-establishment of the glial pathway. Transplantation of glial cells into the injury site is therefore a promising therapeutic approach for repair spinal cord injury (Oudega and Xu, 2006).

Glial cell transplantation addresses many of the challenges that must be overcome for successful functional improvement, including (1) re-establishment of a growth-promoting environment, (2) replacement of lost cell populations (neurons and glia), and (3) facilitation and promotion of axonal regeneration and extension. Pioneering studies have established that transplantation of glial cells can improve axonal repair, enhance re-growth of damaged nerve cells and improve functional recovery (Yan et al., 2001; Santos-Benito and Ramon-Cueto, 2003). Additionally, glial cells have the potential to produce neurotrophic molecules that activate axon regeneration and extension (Jones et al., 2003; Feron et al., 2005).

Different types of glial cells have been investigated as treatment for spinal cord injury including Schwann cells from peripheral nerves and OECs. Schwann cells have been trialled for transplantation due to the important role they play in axon regeneration and myelination. Schwann cells transplanted to the damaged spinal cord can stimulate regeneration of damaged neurons, presumably due to the production of neurotrophic factors (Park et al., 2010), and can also enhance axon remyelination and extension (Lavdas et al., 2010; Flora et al., 2013). However, the axonal regeneration has thus far been limited to restricted areas because Schwann cells have failed to migrate considerable distances into the injured tissue (Lankford et al., 2008). The limited migration is most likely due to unfavorable interaction between the transplanted Schwann cells and host astrocytes (Li et al., 2012). Additionally, Schwann cells have been reported to inhibit myelination 
by the secretion of connective tissue growth factor, whereas OECs do not (Lamond and Barnett, 2013). Thus, Schwann cells may not be the optimal cell type for transplantation therapies due to their poor migration properties, inability to freely interact with endogenous glia and expression of inhibitory molecules.

\subsection{Transplanted OECs in spinal injury models}

Implantation of OECs to promote repair after spinal cord injury have been performed in a variety of spinal cord injury animal models (Table 2). Most of these studies have shown that in rodents with spinal cord injury, OEC transplantation promotes the regeneration of axons (Bartolomei and Greer, 2000; Gudino-Cabrera et al., 2000; Ramer et al., 2004) and improves functional restoration of breathing and climbing ability (Li et al., 2003; Su and He, 2010; Stamegna et al., 2011). In a study of spinal-injured dogs, the transplantation of OECs and fibroblasts restored significant movement in some dogs probably through the restoration of local circuitry, which clearly demonstrates that the procedure has high potential (Granger et al., 2012). Some studies, however, concluded that transplantation of OECs into injured spinal tract did not lead to any detectable difference in axonal extension and functional outcomes (Collazos-Castro et al., 2005; Lu et al., 2006; Chhabra et al., 2009). Discrepancies between results may be attributed to different variables such as the exact nature of spinal cord injury, OEC isolation and culture protocols, transplantation procedure (site of the OECS transplantation and the time after injury that the transplantation is performed) and methodology used to assess outcome.

Numerous studies have reported significant functional improvements following transplantation of OECs. In rodents, OEC transplantation improved or preserved local circuitry as detected electrophysiologically (Toft et al., 2007), and has improved fore-paw movement (Yamamoto et al., 2009), motor function (Munoz-Quiles et al., 2009; Centenaro et al., 2011; Stamegna et al., 2011), hindlimb function (Salehi et al., 2009; Amemori et al., 2010; Aoki et al., 2010; Ziegler et al., 2011), 
plantar function (Amemori et al., 2010), locomotor function (Ma et al., 2010) and diaphragm activity (Tharion et al., 2011). Thus depending on the type of injury and the assessment of particular functional tests, OEC transplantation can improve functional outcomes.

Corresponding anatomical outcomes after OEC transplantation have also been detected with the majority of studies focusing on axon growth and reduction in cavity formation and astrocytic scarring (Amemori et al., 2010; Centenaro et al., 2011; Tharion et al., 2011; Zhang et al., 2011; Toft et al., 2013; Torres-Espin et al., 2014). The reduction in cavity formation and astrocytic scarring are considered important features as they preserve the axonal circuitry and reduce the formation of physical barriers that prevent axonal growth. In these situations, OECs could be considered to indirectly promoting axon growth as they are enhancing the local environment to make it subsequently amenable to axon growth across the injury site.

However, anatomical improvements are not always detected despite functional recovery being observed. Significant restoration of fore-paw retrieval but not axon regeneration (Yamamoto et al., 2009) may indicate local circuitry changes outside of the immediate injury site as has been suggested for restoration of function in dogs (Granger et al., 2012) or may indicate improved preservation of function of the spared axons.

The timing of transplantation of OECs may also be important for anatomical and functional outcomes. Acute transplantation of OECs may be preferable as the potential ability of OECs to reduce cavity formation and reduce the creation of an inhibitory environment would likely promote axon regeneration. Indeed, acute transplantation of OECs has shown higher functional and anatomical outcomes compared to delayed transplant (Lopez-Vales et al., 2006). However, other studies have not detected significant differences in outcomes for acute versus delayed transplantation of OECs (Munoz-Quiles et al., 2009; Centenaro et al., 2011; Torres-Espin et al., 
2014). Despite this, it would seem reasonable that differences in efficacy and outcomes of acute versus delayed treatment may be revealed if improvements in the experimental conditions were made and the purity of the cell preparations and co-transplanted cells was optimized (as discussed below).

What are the mechanisms by which OECs promote regeneration of the spinal cord? OECs transplanted into spinal cord lesions promote regeneration of axons across the lesion, remyelination of axons (although the mechanism remains unknown) and resumption of numerous cellular functions (Ramon-Cueto, 2000; Santos-Benito and Ramon-Cueto, 2003; Ramer et al., 2004; Li et al., 2012). In particular, OECs provide a physical "bridge” which assists directional regeneration of severed axons across injury sites (Ramon-Cueto and Nieto-Sampedro, 1994; Boruch et al., 2001; Resnick et al., 2003) which is consistent with the role of OECs within the injured olfactory system where it has been shown that OECs migrate ahead of axons and that superior axon regeneration occurs when a substantial OEC environment has been created (Chehrehasa et al., 2010). Different factors such as GDNF and NGF have been identified to regulate migration of OECs (Cao et al., 2004; Windus et al., 2007). For example, when OECS are genetically modified to express higher levels of GDNF they display a superior ability to promote axonal growth (Cao et al., 2004). On a cellular level, GDNF acts by stimulating the behaviour of the peripheral lamellipodial waves, increasing cell-cell contact and contact-dependent migration (Windus et al., 2007). Indeed, it has been demonstrated that the motility of OECs in vitro is directly responsible for the apparent motility of axons due to the preference for axons to adhere to OECs (Windus et al., 2011). Thus the migration of OECs across the spinal cord injury site creates a physical glial bridge rich in axon growth promoting factors which together is likely to enhance axon regeneration.

OECs are also thought to be superior to other glial cell types in their interactions with astrocytes. OECs do not tend to form barriers with astrocytes but instead intermix with the astrocytes and 
thereby reduce the formation of the astrocytic scar (Ramon-Cueto and Avila, 1998; Lakatos et al., 2000; Fairless and Barnett, 2005; Santos-Silva et al., 2007). Again, this is consistent with their in vivo role in the olfactory system where OECs of the inner nerve fibre layer interact extensively with the astrocytes that populate the more internal layers of the olfactory bulb (Figure 3F; Lakatos et al., 2000).

The phagocytic activity of OECs (Wewetzer et al., 2005; Su et al., 2013) may also improve the local environment of the injury site by removing cellular debris and thereby reducing the inhibitory factors that prevent axon regeneration. It has been clearly shown that OECs phagocytose axon debris within the olfactory system and in vitro (Wewetzer et al., 2005; Su et al., 2013), as well as within the injured spinal cord (Lankford et al., 2008).

In summary, the likely benefits of transplantation of OECs are that they migrate across the injury site to form a glial bridge rich in axon growth promoting factors, they reduce cavity formation, they interact with astrocytes to reduce scar formation, and they likely phagocytose axon debris from the damaged cells to rapidly create an environment favourable for axon regeneration (Figure 4).

\subsection{Human trials of OEC transplantation into the injured spinal cord}

Several human clinical trials have demonstrated that transplantation of OECs, of both autologous and of embryonic origin, is a safe and feasible treatment (Yan et al., 2001; Feron et al., 2005; Lima et al., 2006; Tabakow et al., 2013), even after three years post-implantation (Mackay-Sim et al., 2008; Huang et al., 2012). A Phase I clinical trial used autologous transplantation of OECs purified from nasal biopsies of spinal cord injury patients and showed that patients with chronic spinal cord injury did not show any adverse medical or surgical complications from the procedure, such as neuropathic pain or neurological deterioration (Feron et al., 2005; Mackay-Sim et al., 2008). In a more recent Phase I study, the transplantation of OECs together with fibroblasts was shown to be 
safe and feasible after one year (Tabakow et al., 2013). Another study showed partial recovery of bladder sensation and improvement of motor function scores in SCI patients transplanted with autologous non-purified OECs (whole olfactory mucosa grafts) (Lima et al., 2006) although this study was not conducted in accordance with Phase I or II standards and thus limited conclusions can be drawn from this study. Huang et al. (2003) reported improvement in both motor function scores and sensory perception in spinal cord injury patients aged 2 to 64 that received transplantation of human embryonic OECs cells, however, these results have been questioned for failing to meet safety standards for scientific protocols (Lim and Tow, 2007). Encouraging results have indicated that OEC transplantation is a promising and safe option to improve recovery in human spinal cord injury patients. However, a more accurate, standardised experimental design, including appropriate controls as well as a larger number of patients, is needed in further clinical trials to confirm the feasibility and effectiveness of OEC therapy. The number of human trials conducted to date is not sufficient to conclude which degree of OEC purity is optimal. In the Phase I trial conducted by Feron et al. (2005) purified lamina propria-derived OECs from nasal biopsies were transplanted and shown to be safe, albeit no dramatic functional improvement was achieved (Feron et al., 2005; Mackay-Sim et al., 2008). Other groups (Lima et al., 2006; Chhabra et al., 2009; Aoki et al., 2010) used whole olfactory mucosa grafts (a mix of neural stem cells, OECs, fibroblasts and other associated cells) to fill the lesion cavity. In these studies some patients were reported to show improvement on motor functional and sensory neurological scores; however some adverse effects such as neuropathic pain were reported, and appropriate controls for strict comparisons were not included. The large expense and ethical concerns of conducting human trials, particularly those with large numbers of patients, confers the need to determine the optimal cell purity and cell mix to maximise the likelihood of successful outcomes. Therefore prior to conducting future human trials, it is important that the methods for purifying and identifying OECs and whether the inclusion of additional cell types is favourable should be addressed. 


\subsection{OECs are a heterogeneous population - which source should be used?}

Within the olfactory system in vivo, OECs are not all the same, but have different characteristics and roles depending on their location in the olfactory nerve pathway. Are these different characteristics relevant for spinal repair therapies and are the differences in the OEC subpopulations maintained after culturing and after transplantation? If so, then the source of OECs that are selected for transplantation is likely to affect the outcomes of spinal repair therapies.

OECs express a range of different molecules depending on their location in the olfactory nerve. OECs within the lamina propria express $\mathrm{p} 75^{\mathrm{NTR}}$ and $\mathrm{S} 100 \beta$ which are typically used to confirm the identity and purity of OECs that have been cultured (Table 2). OECs within the nerve fibre layer of the olfactory bulb are not homogeneous and two OEC subpopulations are present (Figure 2) which each express distinct markers. The nerve fibre layer of the olfactory bulb can be further subdivided into outer and inner layers that contain different populations of OECs with different roles in vivo. OECs of the outer nerve fibre layer are responsible for the defasciculation and sorting of axons, and inner nerve fibre layer OECs, refasciculate and target axons to glomeruli (Figure 2). Expression of OEC markers also differs between the subpopulations with OECs in the outer nerve fibre layer highly expressing S100 $\beta$ protein and p75 ${ }^{\mathrm{NTR}}$ (Gong et al., 1994; Au et al., 2002), whereas, OECs in the inner nerve fibre layer express low levels of $\mathrm{S} 100 \beta$ and $\mathrm{p} 75^{\mathrm{NTR}}$, but do express high levels of TROY (Hisaoka et al., 2004) and NPY (Ubink and Hokfelt, 2000). Therefore, based simply upon the differential expression of these markers, OECs can be considered to be a heterogeneous population of cells each with distinct characteristics that may confer different benefits for regenerating axons. 
What are the proposed roles of OECs for the guidance and targeting of olfactory axons? Within the lamina propria, OECs (green in Figure 2) ensheathe fascicles of axons that arise from neurons expressing different odorant receptor types. When the axon fascicles reach the outer layer of the nerve fibre layer, the OECs (red in Figure 2) contribute to the defasciculation and sorting of the axons as they search for their target glomeruli. Within the inner nerve fibre layer, the OECs (blue in Figure 2) contribute to the refasciculation and targeting of axons according to their odorant receptor type. Thus the OECs play different roles in these three different regions: (i) fasciculation within the lamina propria; (ii) defasciculation and sorting within the outer layer of the nerve fibre layer; (iii) refasciculation and targeting within the inner layer of the nerve fibre layer.

Consistent with their in vivo roles, in vitro studies have shown that OECs that have been purified from different regions of the olfactory system have distinctly different behaviours during cell-cell contact (Windus et al., 2007; Windus et al., 2010; Roloff et al., 2013). Canine OECs from the olfactory bulb have been shown to migrate faster than OECs from the lamina propria (Roloff et al., 2013). In other studies, mouse OECs from the lamina propria tend to adhere to each other, consistent with their need to promote fasciculation (Windus et al., 2007). In contrast, OECs from the nerve fibre layer of the olfactory bulb exhibit various reactions to cell-cell contact including adhesion and repulsion consistent with their roles in mediating defasciculation of axons, refasciculation and targeting (Windus et al., 2010). When olfactory sensory neurons were cocultured with different sources of OECs, axons formed fascicle-like structures with OECs from the lamina propria whereas they tended to disperse when grown with OECs from the olfactory bulb (Windus et al., 2010). In addition, OECs derived from different regions of the nerve fibre layer (rostral, dorsal, caudal, ventral) also exhibit varying responses (Windus et al., 2010). A lack of consistency in the purification of OECs from the olfactory bulb may account for the variation in results that are observed in the spinal transplant models. Some protocols purify OECs from the 
entire nerve fibre layer of the olfactory bulb (Li et al., 1997; Ramon-Cueto, 2000; Lopez-Vales et al., 2006; Li et al., 2007), while other protocols specify a more restricted region of the nerve fibre layer such as the rostral region (Lankford et al., 2008) or the ventral region (Guest et al., 2008). In other protocols, the region of the nerve fibre layer has not been specified (Teng et al., 2008; TorresEspin et al., 2014) although it may be that the entire nerve fibre layer was used. Thus selecting the source of OECs could have crucial influences on the efficacy of these cells for repair of the injured spinal cord. Consistent with this, in vivo transplantation has demonstrated variable outcomes depending on the source of OECs that have been used. After transplantation into a crush injury model, OECs from the lamina propria migrated more extensively and reduced the size of the lesion cavity which resulted in more extensive axon sprouting compared to the results obtained after transplantation of OECs derived from the olfactory bulb (Richter et al., 2005). However, olfactory bulb derived OECs promoted greater angiogenesis and reduced autotomy (Richter et al., 2005). In other studies, however, the variation in outcomes depending on the source of OECs is less clear. High purity cultures of OECs from the lamina propria and from the olfactory bulb have both been shown to give similar results in reducing scar formation and promoting axon extension in comparison to control groups (Mayeur et al., 2013). If the OECs derived from the lamina propria give similar therapeutic outcomes compared to OECs derived from the olfactory bulb, then the use of the lamina propria OECs would be preferred for human therapies due to the ease of accessing the source of OECs from the olfactory mucosa.

OECs derived from the olfactory bulb offer other advantages that may make their use preferable. Typically, due to the amount of tissue that can be obtained from the nerve fibre layer, OECs from the olfactory bulb are easier to purify, result in large cell numbers, and have fewer contaminating cells such as fibroblasts (discussed below) which makes their use for animal trials attractive. Certainly, numerous studies have demonstrated improvements in anatomical or functional outcomes 
using OECs derived from the olfactory bulb (Table 2). In humans, the use of olfactory bulb derived OECs is feasible although much more invasive and primate studies have demonstrated that OECs can be successfully grown from olfactory bulbs (Rubio et al., 2008).

\subsection{Purification of OECs and contaminating cells}

One of the advantages of using OECs from the lamina propria for spinal repair therapies is that they can be easily harvested from the patient's own nasal mucosa. A small biopsy from the dorsal/caudal region of the nasal cavity can be obtained using local anaesthetic with minimal risk of complication. The OECs are then cultured in vitro to undergo population expansion and transplanted back into the same patient in the spinal injury site. This autologous transplantation avoids host recognition problems however it necessitates a window of several weeks while sufficient cells are expanded in culture. Therefore early intervention to treat the spinal injury cannot occur with this method. An alternative approach is to generate a bank of purified non-autologous OECs that is stored and ready for immediate transplantation for newly injured patients. To this end, extensive work has been conducted using rodent and canine models to identify protocols that result in purification of OECs and to enhance the proliferation of the cells in vitro.

In animal models, OECs can be purified from either the olfactory mucosa lining the nasal cavity or from the nerve fibre layer of the olfactory bulb. Both of these different sources have advantages and disadvantages. Within the olfactory mucosa, the axons of the olfactory sensory neurons form large fascicles surrounded by the OECs (Figure 3A). By dissecting out the mucosa, or separating the lamina propria from the overlying olfactory epithelium, the OECs can be isolated from the explant tissue. However, other cell types are also present within the lamina propria which can potentially contaminate the cultures. The accessory olfactory nerve (part of the pheromone detection system in 
non-human mammals) projects along the septum and is often adjacent to the fascicles of the main olfactory system (Figure 3B). To date, there has been no systemic comparison of the potential contamination of OEC cultures with accessory olfactory OECs and the possible differences in their contribution to spinal cord repair.

The branches of the trigeminal nerve in which the Schwann cells are present can be in close proximity to the olfactory nerve fascicles (Figure 3C). In transgenic S100ß-DsRed reporter mice (Windus et al., 2007) the different morphologies and structures of the olfactory versus the trigeminal nerves are clearly distinguishable (Figure 3D-E), but the close proximity of the trigeminal nerves means that cultures of cells obtained from olfactory mucosa are likely to contain both OECs and Schwann cells unless purification techniques to remove the Schwann cells are employed. For example, in dogs, HNK-1 is a marker of Schwann cells that is not expressed by OECs and the use of magnet-activated cell sorting based on HNK-1 is effective in removing the Schwann cells to obtain populations of OECs that are free of Schwann cells (Ziege et al., 2013). However, in mice there are no such suitable differential cell surface markers that have been identified to date that can be used to separate OECs and Schwann cells effectively. Comparisons have been made between the efficacy of Schwann cells versus OECs for repair of the injured spinal cord with the results typically showing that both OECs and Schwann cells can enhance the anatomical or functional outcomes although with differences between the cell types depending on the assay (Lankford et al., 2008; Li et al., 2012; Barbour et al., 2013). While the proportion of contaminating Schwann cells is likely to be low in OEC cultures, it should still be considered that Schwann cells could be contributing to the results of spinal repair transplantation studies and may be a source of the variation in outcomes that are observed. 
Fibroblasts are also present in the olfactory nerve and often contaminate OEC cultures. To date, most research efforts have attempted to purify the OECs using sedimentation techniques and complement- or antibody-mediated purification techniques with the purpose to eliminate fibroblasts. However, in many cases, partially purified or unpurified mucosal tissues have been used with variable outcomes (Table 2). It has been proposed that the inclusion of fibroblasts with the OECs is essential for the functional improvements (Raisman and Li, 2007) and transplantation of mixed olfactory cell populations (OECs + olfactory nerve fibroblasts) has resulted in enhanced recovery of motor function in rats when compared to OECs or fibroblasts alone, and suggested that the presence of the two cell types is necessary for optimal repair (Li et al., 2003). Recently, transplantation of semi-purified olfactory mucosa-derived cells (around 50\% OECs; the remainder being fibroblasts) in dogs with spinal cord injury demonstrated that functional recovery can be achieved (Granger et al., 2012). Dogs that received the autologous cells reported a significant gain of fore-hind limb coordination as well as an improvement in the communication across the damaged segments of the spinal cord. In contrast, it has been reported that the presence of fibroblasts on olfactory mucosa cultures used for transplantation results in higher numbers of activated astrocytes, as well as an increase in inhibitory extracellular molecules that reduce axonal regeneration when compared with transplantation of pure glial cells populations (Toft et al., 2013).

To date, the roles of fibroblasts in neuronal regeneration remain relatively uncharacterised, but emerging data suggest that these cells do have crucial and active roles significantly beyond those of inactive connective tissue cells. When fibroblasts are transplanted with neural progenitor cells, they provide a scaffold that facilitates axonal re-growth after spinal cord injury (Pfeifer et al., 2004). Furthermore, fibroblasts are able to populate the lesion cavity in damaged spinal cord (Vroemen et al., 2007) and cause neural progenitor cells to differentiate into glial lineage cells (Wu et al., 2013). Thus, it is evident that a characterisation of how OECs interact with fibroblasts and regenerating 
neurons in a multi-cellular environment is crucial, and the optimal ratio of cells needs to be determined. For example, in peripheral nerve repair it has been shown that fibroblasts organise and promote the migration of Schwann cells (Parrinello et al., 2010), but the effect of fibroblasts on the organization and growth of OECs has not been studied extensively. There is also a question of the method used to identify OECs and fibroblasts in vitro. The marker $\mathrm{p} 75^{\mathrm{NTR}}$ is the principal one used to identify OECs in vitro, however cultured human fibroblasts have been shown to also express p75 ${ }^{\mathrm{NTR}}$ (Garcia-Escudero et al., 2012). This raises the question of whether the cultures of reported high purity OECs in fact contain fibroblasts and whether the therapeutic outcomes in the spinal injury models are due solely to the OECs or rather to the combination of OECs and fibroblasts.

The inclusion of fibroblasts and other cells within the "purified" OEC preparations means that the purity of the cultures varies considerably. For those experiments which have sought to use pure OEC preparations, the majority have reported the percentage of cells that express $\mathrm{p} 75^{\mathrm{NTR}}$ as being over 90\% (Table 2), while others have used preparations of OECs with less purity (e.g. Amemori et al., 2010; Table 2), but still achieve functional outcomes. Other studies have deliberately included other cells such as fibroblasts within preparations with reported purities such as $50 \%$ p $75^{\mathrm{NTR}}$ positive cells (OECs) and 50\% fibroblasts (Table 2). However, in a Phase I trial for humans in which the autologous purification strategies aimed to transplant high purity OECs, a lower purity was reached (76-88\%; Feron et al., 2005). In other autologous transplantation trials in which fibroblasts were deliberately included, the variation in purity of the separate cell preparations was high, with 20-50\% S100 positive cells (OECs) for a human trial (Tabakow et al., 2013) and 30-70\% for dogs (Granger et al., 2012). This indicates that the purification protocols do not result in predictable purities of cells or that the verification techniques (usually immunocytochemistry staining using antibodies against $\mathrm{p} 75^{\mathrm{NTR}}$ and/or S100) are insufficiently accurate. For OEC transplantation to become a realistic therapy for treating the injured spinal cord, it is crucial that 
protocols are developed to improve the reliability of purifying, expanding and verifying the identity of cultures of OECs and/or fibroblasts.

\section{Limitations of the use of OECs}

One of the disadvantages of using OECs for transplantation is the limited survival and low proliferation rates observed over time in culture (Doucette, 2002), making large-scale expansion of OECs a main challenge. Moreover, changes in the local environment may induce changes in the morphology of OECs, affecting their behaviour (Vincent et al., 2005a) and causing cells to exhibit characteristics associated with specific roles in nerve regeneration (Doucette, 1995; Woodhall et al., 2003).

OECs display a range of phenotypes in vitro and in vivo, and they are able to transform from one morphology type to another in response to modifications in the culture conditions (Doucette, 1995; Windus et al., 2007; Huang et al., 2008a; Radtke et al., 2010; Windus et al., 2010). In culture, OECs display different morphologies, including a flattened sheet-like morphology (astrocyte-like), bipolar fusiform morphology (Schwann cell-like) and multipolar morphology (Chuah and Au, 1994; Huang et al., 2008b). Morphology of OECs is known to be affected by variables as the method of isolation and purification, cell culture conditions as well as presence of extracellular and intracellular molecules such as cAMP, dBcAMP endothelin-1 and fibulin-3 (Vincent et al., 2003; Huang et al., 2008b; Vukovic et al., 2009). For example, expression of fibulin-3 in OECs results in a predominant bipolar morphology with extremely long processes (Vukovic et al., 2009), whereas local changes in cAMP levels lead to dynamic morphology alterations dramatically affecting OECs migration rate (Huang et al., 2008b). 
Studies have shown that OEC plasticity is more evident after cells have been exposed to activated astrocytes and inflammatory mediators within a neuronal lesion site (Woodhall et al., 2003). This extreme plasticity in morphology and physiological changes in populations of OECs before and after transplantation may be a further cause for the discrepancy of results between studies. Thus, it is necessary to develop an optimal standard method by which OECs can be effectively propagated whilst maintaining a consistent or predictable phenotype. At the very least, a thorough characterisation of the mechanisms involved in regulating OEC morphology and behaviour is critical to guarantee better outcomes for OEC transplantation trials.

Another concern presented in transplantation of glial cells as a therapy for spinal cord injury is the inability of transplanted cells to integrate in the host spinal cord. This is due to the over-expression of proteins that inhibit migration, such as Nogo, known to alter the morphology of lamellipodial membrane protrusions in OECs to favor focal adhesion rather than migration (Xu et al., 2009). Some molecules such as proteoglycans, can block the production of these inhibitory proteins, thus promoting the migration of transplanted cells into injured spinal tracts (Huang et al., 2008a). In an olfactory injury model, it has been demonstrated that OECs migrate more extensively without the presence of axons, but that subsequent axon growth is then superior (Chehrehasa et al., 2010). After transplantation, OECs migrate ahead of regenerating axons through unfavorable growth environments increasing the potential of damaged axons to extend through the damaged site (Ramon-Cueto and Santos-Benito, 2001; Chehrehasa et al., 2010; Ramon-Cueto, 2011). Identification of factors or small molecules that enhance OEC migration properties could offer new alternatives for develop further strategies with emphasis in combinations of cell transplantation and drug therapy that could increase the efficacy of actual OECs transplantation treatments. For example, as described above and has been tested in vivo, OECs could be genetically engineered to express growth factors that would promote their function (Cao et al., 2004; Wu et al., 2008). 


\section{Future outlook and opportunities}

The use of combination therapies involving OEC transplantation and neural growth factors or molecules that mimic their neurotrophic effect are likely to achieve better results than conventional therapies, and provide a more efficient solution for neural repair in humans (Doucette, 1995). Neuregulins and other neurotrophic factors are involved in the survival, proliferation and migration of OECs, as well as Schwann cells, oligodendrocytes and astrocytes. All different types of glial cells present receptors for neuregulins, molecules that promote glial growth and regulate the role of glial cells on nerve regeneration. OECs express various neuregulins including Neu differentiation factor, glial growth factor and motor-neuron derived factor, as well as many receptors for these molecules, supporting the theory that OECs play an important role in the survival, growthpromotion and regeneration of severed nerve cells (Woodhall et al., 2001; Woodhall et al., 2003; Vincent et al., 2005a). An increased understanding of how glial cells respond to neurotrophic molecules as well as the identification of novel compounds that enhance the migratory and integrative properties of OECs is therefore highly warranted in the field.

Another approach is the use of biomaterials and tissue engineering strategies that facilitate axon growth in the spinal cord, as well as to enhance the survival and integration of OECs or other cells transplanted to the injury site. Extracellular matrix motifs and bio-scaffolds can provide the transplanted cells with an enriched substrate that may increase cell proliferation and migration. For example, matrix proteins such as fibronectin and laminin, used on matrix-based scaffold have antiapoptotic properties that may lead to an improvement on cell survival and migration (Friedman et al., 2002b; Friedman et al., 2002a).

To date, experimental and clinical studies suggest that OEC transplantation is safe and effective and may provide real benefits in the treatment of spinal cord injuries. However, it is important that a 
better understanding of the biology of OECs be pursued to enable new strategies to be developed, perhaps with a more multi-faceted approach, to achieve an effective use of OECs in the treatment of spinal cord injury in humans. 


\section{References}

Amemori T, Jendelova P, Ruzickova K, Arboleda D, Sykova E (2010) Co-transplantation of olfactory ensheathing glia and mesenchymal stromal cells does not have synergistic effects after spinal cord injury in the rat. Cytotherapy 12:212-225.

Antonic A, Sena ES, Lees JS, Wills TE, Skeers P, Batchelor PE, Macleod MR, Howells DW (2013) Stem cell transplantation in traumatic spinal cord injury: a systematic review and metaanalysis of animal studies. PLoS Biol 11:e1001738.

Aoki M, Kishima H, Yoshimura K, Ishihara M, Ueno M, Hata K, Yamashita T, Iwatsuki K, Yoshimine $\mathrm{T}$ (2010) Limited functional recovery in rats with complete spinal cord injury after transplantation of whole-layer olfactory mucosa: laboratory investigation. J Neurosurg Spine 12:122-130.

Arevalo MA, Santos-Galindo M, Bellini MJ, Azcoitia I, Garcia-Segura LM (2010) Actions of estrogens on glial cells: Implications for neuroprotection. Biochim Biophys Acta 1800:1106-1112.

Au WW, Treloar HB, Greer CA (2002) Sublaminar organization of the mouse olfactory bulb nerve layer. J Comp Neurol 446:68-80.

Barbour HR, Plant CD, Harvey AR, Plant GW (2013) Tissue sparing, behavioral recovery, supraspinal axonal sparing/regeneration following sub-acute glial transplantation in a model of spinal cord contusion. BMC Neurosci 14:106.

Barraud P, St John JA, Stolt CC, Wegner M, Baker CV (2013) Olfactory ensheathing glia are required for embryonic olfactory axon targeting and the migration of gonadotropin-releasing hormone neurons. Biol Open 2:750-759.

Barraud P, Seferiadis AA, Tyson LD, Zwart MF, Szabo-Rogers HL, Ruhrberg C, Liu KJ, Baker CV (2010) Neural crest origin of olfactory ensheathing glia. Proc Natl Acad Sci U S A 107:21040-21045.

Bartolomei JC, Greer CA (2000) Olfactory ensheathing cells: bridging the gap in spinal cord injury. Neurosurgery 47:1057-1069.

Batzofin BM, Weiss YG, Ledot SF (2013) Do corticosteroids improve outcome for any critical illness? Current Opinion in Anesthesiology 26:164-170.

Beattie MS, Bresnahan JC, Komon J, Tovar CA, Van Meter M, Anderson DK, Faden AI, Hsu CY, Noble LJ, Salzman S, Young W (1997) Endogenous repair after spinal cord contusion injuries in the rat. Exp Neurol 148:453-463.

Block ML, Hong JS (2005) Microglia and inflammation-mediated neurodegeneration: multiple triggers with a common mechanism. Prog Neurobiol 76:77-98.

Bolton AE (2005) Biologic effects and basic science of a novel immune-modulation therapy. Am J Cardiol 95:24C-29C; discussion 38C-40C.

Boruch AV, Conners JJ, Pipitone M, Deadwyler G, Storer PD, Devries GH, Jones KJ (2001) Neurotrophic and migratory properties of an olfactory ensheathing cell line. Glia 33:225229.

Bunge RP, Bunge MB, Rish (1960) Electron microscopic study of demyelination in an experimentally induced lesion in adult cat spinal cord. J Biophys Biochem Cytol 7:685-696.

Byrnes KR, Stoica B, Riccio A, Pajoohesh-Ganji A, Loane DJ, Faden AI (2009) Activation of metabotropic glutamate receptor 5 improves recovery after spinal cord injury in rodents. Annals of Neurology 66:63-74.

Cabezas R, El-Bacha RS, Gonzalez J, Barreto GE (2012) Mitochondrial functions in astrocytes: neuroprotective implications from oxidative damage by rotenone. Neurosci Res 74:80-90.

Cao L, Zhu YL, Su ZD, Lv BL, Huang ZH, Mu LF, He C (2007) Olfactory ensheathing cells promote migration of Schwann cells by secreted nerve growth factor. Glia 55:897-904.

Cao L, Liu L, Chen ZY, Wang LM, Ye JL, Qiu HY, Lu CL, He C (2004) Olfactory ensheathing cells genetically modified to secrete GDNF to promote spinal cord repair. Brain 127:535549. 
Centenaro LA, Jaeger MD, Ilha J, de Souza MA, Kalil-Gaspar PI, Cunha NB, Marcuzzo S, Achaval M (2011) Olfactory and respiratory lamina propria transplantation after spinal cord transection in rats: Effects on functional recovery and axonal regeneration. Brain Research 1426:54-72.

Chatzipanteli K, Garcia R, Marcillo AE, Loor KE, Kraydieh S, Dietrich WD (2002) Temporal and segmental distribution of constitutive and inducible nitric oxide synthases after traumatic spinal cord injury: effect of aminoguanidine treatment. J Neurotrauma 19:639-651.

Chehrehasa F, Ekberg JA, Lineburg K, Amaya D, Mackay-Sim A, St John JA (2012) Two phases of replacement replenish the olfactory ensheathing cell population after injury in postnatal mice. Glia 60:322-332.

Chehrehasa F, Windus LC, Ekberg JA, Scott SE, Amaya D, Mackay-Sim A, St John JA (2010) Olfactory glia enhance neonatal axon regeneration. Mol Cell Neurosci 45:277-288.

Chhabra HS, Lima C, Sachdeva S, Mittal A, Nigam V, Chaturvedi D, Arora M, Aggarwal A, Kapur R, Khan TA (2009) Autologous olfactory [corrected] mucosal transplant in chronic spinal cord injury: an Indian Pilot Study. Spinal Cord 47:887-895.

Chuah MI, Zheng DR (1992) The human primary olfactory pathway: fine structural and cytochemical aspects during development and in adults. Microscopy Research and Technique 23:76-85.

Chuah MI, Au C (1994) Olfactory Cell-Cultures on Ensheathing Cell Monolayers. Chemical Senses 19:25-34.

Chuah MI, Teague R (1999) Basic fibroblast growth factor in the primary olfactory pathway: Mitogenic effect on ensheathing cells. Neuroscience 88:1043-1050.

Chuah MI, Hale DM, West AK (2011) Interaction of olfactory ensheathing cells with other cell types in vitro and after transplantation: glial scars and inflammation. Exp Neurol 229:46-53.

Chuah MI, Choi-Lundberg D, Weston S, Vincent AJ, Chung RS, Vickers JC, West AK (2004) Olfactory ensheathing cells promote collateral axonal branching in the injured adult rat spinal cord. Exp Neurol 185:15-25.

Chugani DC, Kedersha NL, Rome LH (1991) Vault immunofluorescence in the brain: new insights regarding the origin of microglia. J Neurosci 11:256-268.

Chung RS, Woodhouse A, Fung S, Dickson TC, West AK, Vickers JC, Chuah MI (2004) Olfactory ensheathing cells promote neurite sprouting of injured axons in vitro by direct cellular contact and secretion of soluble factors. Cell Mol Life Sci 61:1238-1245.

Chung WS, Barres BA (2011) The role of glial cells in synapse elimination. Curr Opin Neurobiol.

Collazos-Castro JE, Muneton-Gomez VC, Nieto-Sampedro M (2005) Olfactory glia transplantation into cervical spinal cord contusion injuries. Journal of Neurosurgery-Spine 3:308-317.

Doucette JR (1984) The glial cells in the nerve fiber layer of the rat olfactory bulb. Anat Rec 210:385-391.

Doucette R (1990) Glial influences on axonal growth in the primary olfactory system. Glia 3:433449.

Doucette R (1995) Olfactory Ensheathing Cells - Potential for Glial-Cell Transplantation into Areas of Cns Injury. Histology and Histopathology 10:503-507.

Doucette R (2002) Olfactory ensheathing cells: Past, present and future. Faseb Journal 16:A751A751.

Doucette R, Devon R (1993) Olfactory Ensheathing Cells - Factors Influencing the Phenotype of These Glial-Cells. Biology and Pathology of Astrocyte-Neuron Interactions 2:117-124.

Ekberg JA, Amaya D, Chehrehasa F, Lineburg K, Claxton C, Windus LC, Key B, Mackay-Sim A, St John JA (2011) OMP-ZsGreen fluorescent protein transgenic mice for visualisation of olfactory sensory neurons in vivo and in vitro. J Neurosci Methods 196:88-98.

Fairless R, Barnett SC (2005) Olfactory ensheathing cells: their role in central nervous system repair. Int J Biochem Cell Biol 37:693-699.

Farbman AI, Squinto LM (1985) Early Development of Olfactory Receptor Cell Axons. Developmental Brain Research 19:205-213. 
Feron F, Perry C, Cochrane J, Licina P, Nowitzke A, Urquhart S, Geraghty T, Mackay-Sim A (2005) Autologous olfactory ensheathing cell transplantation in human spinal cord injury. Brain 128:2951-2960.

Flora G, Joseph G, Patel S, Singh A, Bleicher D, Barakat DJ, Louro J, Fenton S, Garg M, Bunge MB, Pearse DD (2013) Combining neurotrophin-transduced schwann cells and rolipram to promote functional recovery from subacute spinal cord injury. Cell Transplant 22:22032217.

Friedman JA, Windebank AJ, Yaszemski MJ, Moore MJ, Lewellyn EB (2002a) A Schwann cellseeded, biodegradable polymer implant for promoting axon regeneration after spinal cord injury. Annals of Neurology 52:S87-S87.

Friedman JA, Windebank AJ, Moore MJ, Spinner RJ, Currier BL, Yaszemski MJ (2002b) Biodegradable polymer grafts for surgical repair of the injured spinal cord. Neurosurgery 51:742-751.

Gao Z, Zhu Q, Zhang Y, Zhao Y, Cai L, Shields CB, Cai J (2013) Reciprocal modulation between microglia and astrocyte in reactive gliosis following the CNS injury. Mol Neurobiol 48:690701.

Garcia-Escudero V, Garcia-Gomez A, Langa E, Martin-Bermejo MJ, Ramirez-Camacho R, GarciaBerrocal JR, Moreno-Flores MT, Avila J, Lim F (2012) Patient-derived olfactory mucosa cells but not lung or skin fibroblasts mediate axonal regeneration of retinal ganglion neurons. Neurosci Lett 509:27-32.

Gong Q, Bailey MS, Pixley SK, Ennis M, Liu W, Shipley MT (1994) Localization and regulation of low affinity nerve growth factor receptor expression in the rat olfactory system during development and regeneration. J Comp Neurol 344:336-348.

Granger N, Blamires H, Franklin RJ, Jeffery ND (2012) Autologous olfactory mucosal cell transplants in clinical spinal cord injury: a randomized double-blinded trial in a canine translational model. Brain 135:3227-3237.

Graziadei PP, Levine RR, Graziadei GA (1978) Regeneration of olfactory axons and synapse formation in the forebrain after bulbectomy in neonatal mice. Proc Natl Acad Sci U S A 75:5230-5234.

Gudino-Cabrera G, Pastor AM, de la Cruz RR, Delgado-Garcia JM, Nieto-Sampedro M (2000) Limits to the capacity of transplants of olfactory glia to promote axonal regrowth in the CNS. Neuroreport 11:467-471.

Guest JD, Herrera L, Margitich I, Oliveria M, Marcillo A, Casas CE (2008) Xenografts of expanded primate olfactory ensheathing glia support transient behavioral recovery that is independent of serotonergic or corticospinal axonal regeneration in nude rats following spinal cord transection. Exp Neurol 212:261-274.

Hermann GE, Rogers RC, Bresnahan JC, Beattie MS (2001) Tumor necrosis factor-alpha induces cFOS and strongly potentiates glutamate-mediated cell death in the rat spinal cord. Neurobiol Dis 8:590-599.

Hisaoka T, Morikawa Y, Kitamura T, Senba E (2004) Expression of a member of tumor necrosis factor receptor superfamily, TROY, in the developing olfactory system. Glia 45:313-324.

Huang H, Wang H, Chen L, Gu Z, Zhang J, Zhang F, Song Y, Li Y, Tan K, Liu Y, Xi H (2006) Influence factors for functional improvement after olfactory ensheathing cell transplantation for chronic spinal cord injury. Zhongguo Xiu Fu Chong Jian Wai Ke Za Zhi 20:434-438.

Huang H, Chen L, Wang H, Xiu B, Li B, Wang R, Zhang J, Zhang F, Gu Z, Li Y, Song Y, Hao W, Pang S, Sun J (2003) Influence of patients' age on functional recovery after transplantation of olfactory ensheathing cells into injured spinal cord injury. Chin Med J (Engl) 116:14881491.

Huang HY, Xi HT, Chen L, Zhang F, Liu YC (2012) Long-Term Outcome of Olfactory Ensheathing Cell Therapy for Patients With Complete Chronic Spinal Cord Injury. Cell Transplantation 21:S23-S31. 
Huang HY, Chen L, Xi HT, Wang HM, Zhang J, Zhang F, Liu YC (2008a) Fetal olfactory ensheathing cells transplantation in amyotrophic lateral sclerosis patients: a controlled pilot study. Clinical Transplantation 22:710-718.

Huang ZH, Wang Y, Cao L, Su ZD, Zhu YL, Chen YZ, Yuan XB, He C (2008b) Migratory properties of cultured olfactory ensheathing cells by single-cell migration assay. Cell Research 18:479-490.

Hulsebosch CE (2002) Recent advances in pathophysiology and treatment of spinal cord injury. Adv Physiol Educ 26:238-255.

Hurlbert RJ, Hadley MN, Walters BC, Aarabi B, Dhall SS, Gelb DE, Rozzelle CJ, Ryken TC, Theodore N (2013) Pharmacological Therapy for Acute Spinal Cord Injury. Neurosurgery 72:93-105.

Jauregui-Huerta F, Ruvalcaba-Delgadillo Y, Gonzalez-Castaneda R, Garcia-Estrada J, GonzalezPerez O, Luquin S (2010) Responses of glial cells to stress and glucocorticoids. Curr Immunol Rev 6:195-204.

Jessen KR (2004) Glial cells. Int J Biochem Cell Biol 36:1861-1867.

Jessen KR (2006) A brief look at glial cells. Novartis Found Symp 276:5-14; discussion 54-17, 275281.

Jones DG, Anderson ER, Galvin KA (2003) Spinal cord regeneration: moving tentatively towards new perspectives. NeuroRehabilitation 18:339-351.

Kafitz KW, Greer CA (1999) Olfactory ensheathing cells promote neurite extension from embryonic olfactory receptor cells in vitro. Glia 25:99-110.

Kigerl KA, Gensel JC, Ankeny DP, Alexander JK, Donnelly DJ, Popovich PG (2009) Identification of two distinct macrophage subsets with divergent effects causing either neurotoxicity or regeneration in the injured mouse spinal cord. J Neurosci 29:13435-13444.

Kingman P (2009) Mechanisms of Secondary Spinal Cord Injury- A 3D scientific animation In.

Kriegstein AR, Gotz M (2003) Radial glia diversity: A matter of cell fate. Glia 43:37-43.

Lakatos A, Franklin RJM, Barnett SC (2000) Olfactory ensheathing cells and Schwann cells differ in their in vitro interactions with astrocytes. Glia 32:214-225.

Lamond R, Barnett SC (2013) Schwann cells but not olfactory ensheathing cells inhibit CNS myelination via the secretion of connective tissue growth factor. J Neurosci 33:1868618697.

Lankford KL, Sasaki M, Radtke C, Kocsis JD (2008) Olfactory ensheathing cells exhibit unique migratory, phagocytic, and myelinating properties in the X-irradiated spinal cord not shared by Schwann cells. Glia 56:1664-1678.

Lavdas AA, Chen J, Papastefanaki F, Chen S, Schachner M, Matsas R, Thomaidou D (2010) Schwann cells engineered to express the cell adhesion molecule L1 accelerate myelination and motor recovery after spinal cord injury. Exp Neurol 221:206-216.

Leal-Filho MB (2011) Spinal cord injury: From inflammation to glial scar. Surg Neurol Int 2:112.

Leung JY, Chapman JA, Harris JA, Hale D, Chung RS, West AK, Chuah MI (2008) Olfactory ensheathing cells are attracted to, and can endocytose, bacteria. Cell Mol Life Sci 65:27322739.

Li BC, Xu C, Zhang JY, Li Y, Duan ZX (2012) Differing Schwann cells and olfactory ensheathing cells behaviors, from interacting with astrocyte, produce similar improvements in contused rat spinal cord's motor function. J Mol Neurosci 48:35-44.

Li Y, Field PM, Raisman G (1997) Repair of adult rat corticospinal tract by transplants of olfactory ensheathing cells. Science 277:2000-2002.

Li Y, Decherchi P, Raisman G (2003) Transplantation of olfactory ensheathing cells into spinal cord lesions restores breathing and climbing. J Neurosci 23:727-731.

Li Y, Field PM, Raisman G (2005) Olfactory ensheathing cells and olfactory nerve fibroblasts maintain continuous open channels for regrowth of olfactory nerve fibres. Glia 52:245-251. 
Li Y, Yamamoto M, Raisman G, Choi D, Carlstedt T (2007) An experimental model of ventral root repair showing the beneficial effect of transplanting olfactory ensheathing cells. Neurosurgery 60:734-740; discussion 740-731.

Lim PAC, Tow AM (2007) Recovery and regeneration after spinal cord injury: A review and summary of recent literature. Annals Academy of Medicine Singapore 36:49-57.

Lima C, Pratas-Vital J, Escada P, Hasse-Ferreira A, Capucho C, Peduzzi JD (2006) Olfactory mucosa autografts in human spinal cord injury: A pilot clinical study. Journal of Spinal Cord Medicine 29:191-203.

Lopez-Vales R, Fores J, Verdu E, Navarro X (2006) Acute and delayed transplantation of olfactory ensheathing cells promote partial recovery after complete transection of the spinal cord. Neurobiol Dis 21:57-68.

Lopez MV, Cuadrado MP, Ruiz-Poveda OM, Del Fresno AM, Accame ME (2007) Neuroprotective effect of individual ginsenosides on astrocytes primary culture. Biochim Biophys Acta 1770:1308-1316.

Lu P, Yang H, Culbertson M, Graham L, Roskams AJ, Tuszynski MH (2006) Olfactory ensheathing cells do not exhibit unique migratory or axonal growth-promoting properties after spinal cord injury. Journal of Neuroscience 26:11120-11130.

Ma YH, Zhang Y, Cao L, Su JC, Wang ZW, Xu AB, Zhang SC (2010) Effect of neurotrophin-3 genetically modified olfactory ensheathing cells transplantation on spinal cord injury. Cell Transplant 19:167-177.

Mackay-Sim A, Kittel P (1991a) Cell dynamics in the adult mouse olfactory epithelium: a quantitative autoradiographic study. J Neurosci 11:979-984.

Mackay-Sim A, Kittel PW (1991b) On the Life Span of Olfactory Receptor Neurons. Eur J Neurosci 3:209-215.

Mackay-Sim A, St John JA (2011) Olfactory ensheathing cells from the nose: Clinical application in human spinal cord injuries. Experimental Neurology 229:174-180.

Mackay-Sim A, Feron F, Cochrane J, Bassingthwaighte L, Bayliss C, Davies W, Fronek P, Gray C, Kerr G, Licina P, Nowitzke A, Perry C, Silburn PAS, Urquhart S, Geraghty T (2008) Autologous olfactory ensheathing cell transplantation in human paraplegia: a 3-year clinical trial. Brain 131:2376-2386.

Matthews MA, St Onge MF, Faciane CL, Gelderd JB (1979) Axon sprouting into segments of rat spinal cord adjacent to the site of a previous transection. Neuropathol Appl Neurobiol 5:181196.

Mayeur A, Duclos C, Honore A, Gauberti M, Drouot L, do Rego JC, Bon-Mardion N, Jean L, Verin E, Emery E, Lemarchant S, Vivien D, Boyer O, Marie JP, Guerout N (2013) Potential of olfactory ensheathing cells from different sources for spinal cord repair. PLoS One 8:e62860.

Mombaerts P, Wang F, Dulac C, Chao SK, Nemes A, Mendelsohn M, Edmondson J, Axel R (1996) Visualizing an olfactory sensory map. Cell 87:675-686.

Munoz-Quiles C, Santos-Benito FF, Liamusi MB, Ramon-Cueto A (2009) Chronic Spinal Injury Repair by Olfactory Bulb Ensheathing Glia and Feasibility for Autologous Therapy. Journal of Neuropathology and Experimental Neurology 68:1294-1308.

Ndubaku U, de Bellard ME (2008) Glial cells: old cells with new twists. Acta Histochem 110:182195.

Novikova LN, Lobov S, Wiberg M, Novikov LN (2011) Efficacy of olfactory ensheathing cells to support regeneration after spinal cord injury is influenced by method of culture preparation. Experimental Neurology 229:132-142.

Oudega M, Xu XM (2006) Schwann cell transplantation for repair of the adult spinal cord. J Neurotrauma 23:453-467.

Panni P, Ferguson IA, Beacham I, Mackay-Sim A, Ekberg JA, St John JA (2013) Phagocytosis of bacteria by olfactory ensheathing cells and Schwann cells. Neuroscience Letters 539:65-70. 
Park HW, Lim MJ, Jung H, Lee SP, Paik KS, Chang MS (2010) Human mesenchymal stem cellderived Schwann cell-like cells exhibit neurotrophic effects, via distinct growth factor production, in a model of spinal cord injury. Glia 58:1118-1132.

Parrinello S, Napoli I, Ribeiro S, Wingfield Digby P, Fedorova M, Parkinson DB, Doddrell RD, Nakayama M, Adams RH, Lloyd AC (2010) EphB signaling directs peripheral nerve regeneration through Sox2-dependent Schwann cell sorting. Cell 143:145-155.

Pearse DD, Chatzipanteli K, Marcillo AE, Bunge MB, Dietrich WD (2003) Comparison of iNOS inhibition by antisense and pharmacological inhibitors after spinal cord injury. J Neuropathol Exp Neurol 62:1096-1107.

Pfeifer K, Vroemen M, Blesch A, Weidner N (2004) Adult neural progenitor cells provide a permissive guiding substrate for corticospinal axon growth following spinal cord injury. European Journal of Neuroscience 20:1695-1704.

Qiu J, Cai D, Dai H, McAtee M, Hoffman PN, Bregman BS, Filbin MT (2002) Spinal axon regeneration induced by elevation of cyclic AMP. Neuron 34:895-903.

Radtke C, Lankford KL, Wewetzer K, Imaizumi T, Fodor WL, Kocsis JD (2010) Impaired spinal cord remyelination by long-term cultured adult porcine olfactory ensheathing cells correlates with altered in vitro phenotypic properties. Xenotransplantation 17:71-80.

Raisman G, Li Y (2007) Repair of neural pathways by olfactory ensheathing cells. Nat Rev Neurosci 8:312-319.

Ramer LM, Au E, Richter MW, Liu J, Tetzlaff W, Roskams AJ (2004) Peripheral olfactory ensheathing cells reduce scar and cavity formation and promote regeneration after spinal cord injury. J Comp Neurol 473:1-15.

Ramon-Cueto A (2000) Olfactory ensheathing glia transplantation into the injured spinal cord. Neural Plasticity and Regeneration 128:265-272.

Ramon-Cueto A (2011) Olfactory ensheathing glia for nervous system repair. Experimental Neurology 229:1-1.

Ramon-Cueto A, Nieto-Sampedro M (1994) Regeneration into the spinal cord of transected dorsal root axons is promoted by ensheathing glia transplants. Exp Neurol 127:232-244.

Ramon-Cueto A, Avila J (1998) Olfactory ensheathing glia: properties and function. Brain Res Bull 46:175-187.

Ramon-Cueto A, Santos-Benito FF (2001) Cell therapy to repair injured spinal cords: Olfactory ensheathing glia transplantation. Restorative Neurology and Neuroscience 19:149-156.

Resnick DK, Cechvala CF, Yan Y, Witwer BP, Sun D, Zhang S (2003) Adult olfactory ensheathing cell transplantation for acute spinal cord injury. J Neurotrauma 20:279-285.

Richter MW, Fletcher PA, Liu J, Tetzlaff W, Roskams AJ (2005) Lamina propria and olfactory bulb ensheathing cells exhibit differential integration and migration and promote differential axon sprouting in the lesioned spinal cord. J Neurosci 25:10700-10711.

Roloff F, Ziege S, Baumgartner W, Wewetzer K, Bicker G (2013) Schwann cell-free adult canine olfactory ensheathing cell preparations from olfactory bulb and mucosa display differential migratory and neurite growth-promoting properties in vitro. BMC Neurosci 14:141.

Rubio MP, Munoz-Quiles C, Ramon-Cueto A (2008) Adult olfactory bulbs from primates provide reliable ensheathing glia for cell therapy. Glia 56:539-551.

Salehi M, Pasbakhsh P, Soleimani M, Abbasi M, Hasanzadeh G, Modaresi MH, Sobhani A (2009) Repair of spinal cord injury by co-transplantation of embryonic stem cell-derived motor neuron and olfactory ensheathing cell. Iran Biomed J 13:125-135.

Santos-Benito FF, Ramon-Cueto A (2003) Olfactory ensheathing glia transplantation: a therapy to promote repair in the mammalian central nervous system. Anat Rec B New Anat 271:77-85.

Santos-Silva A, Fairless R, Frame MC, Montague P, Smith GM, Toft A, Riddell JS, Barnett SC (2007) FGF/heparin differentially regulates Schwann cell and olfactory ensheathing cell interactions with astrocytes: a role in astrocytosis. J Neurosci 27:7154-7167.

Singh S, Swarnkar S, Goswami P, Nath C (2011) Astrocytes and microglia: responses to neuropathological conditions. Int J Neurosci 121:589-597. 
St John JA, Ekberg JA, Dando S, Meedeniya ACB, Horton RE, Batzloff M, Owen SJ, Holt S, Peak IR, Ulett G, Mackay-Sim A, Beacham IR (2014) Burkholderia pseudomallei penetrates the brain via destruction of the olfactory and trigeminal nerves: implications for the pathogenesis of neurological melioidosis. mBIO in press.

Stahel PF, VanderHeiden T, Finn MA (2012) Management strategies for acute spinal cord injury: current options and future perspectives. Current Opinion in Critical Care 18:651-660.

Stamegna JC, Felix MS, Roux-Peyronnet J, Rossi V, Feron F, Gauthier P, Matarazzo V (2011) Nasal OEC transplantation promotes respiratory recovery in a subchronic rat model of cervical spinal cord contusion. Experimental Neurology 229:120-131.

Su Z, He C (2010) Olfactory ensheathing cells: biology in neural development and regeneration. Prog Neurobiol 92:517-532.

Su Z, Yuan Y, Chen J, Cao L, Zhu Y, Gao L, Qiu Y, He C (2009) Reactive astrocytes in glial scar attract olfactory ensheathing cells migration by secreted TNF-alpha in spinal cord lesion of rat. PLoS One 4:e8141.

Su Z, Chen J, Qiu Y, Yuan Y, Zhu F, Zhu Y, Liu X, Pu Y, He C (2013) Olfactory ensheathing cells: the primary innate immunocytes in the olfactory pathway to engulf apoptotic olfactory nerve debris. Glia 61:490-503.

Tabakow P, Jarmundowicz W, Czapiga B, Fortuna W, Miedzybrodzki R, Czyz M, Huber J, Szarek D, Okurowski S, Szewczyk P, Gorski A, Raisman G (2013) Transplantation of Autologous Olfactory Ensheathing Cells in Complete Human Spinal Cord Injury. Cell Transplantation 22:1591-1612.

Teng X, Nagata I, Li HP, Kimura-Kuroda J, Sango K, Kawamura K, Raisman G, Kawano H (2008) Regeneration of nigrostriatal dopaminergic axons after transplantation of olfactory ensheathing cells and fibroblasts prevents fibrotic scar formation at the lesion site. Journal of Neuroscience Research 86:3140-3150.

Tennent R, Chuah MI (1996) Ultrastructural study of ensheathing cells in early development of olfactory axons. Brain Res Dev Brain Res 95:135-139.

Tharion G, Indirani K, Durai M, Meenakshi M, Devasahayam SR, Prabhav NR, Solomons C, Bhattacharji S (2011) Motor recovery following olfactory ensheathing cell transplantation in rats with spinal cord injury. Neurology India 59:77-83.

Tisay KT, Key B (1999) The extracellular matrix modulates olfactory neurite outgrowth on ensheathing cells. J Neurosci 19:9890-9899.

Toft A, Scott DT, Barnett SC, Riddell JS (2007) Electrophysiological evidence that olfactory cell transplants improve function after spinal cord injury. Brain 130:970-984.

Toft A, Tome M, Barnett SC, Riddell JS (2013) A comparative study of glial and non-neural cell properties for transplant-mediated repair of the injured spinal cord. Glia 61:513-528.

Torres-Espin A, Redondo-Castro E, Hernandez J, Navarro X (2014) Bone marrow mesenchymal stromal cells and olfactory ensheathing cells transplantation after spinal cord injury - a morphological and functional comparison in rats. Eur J Neurosci.

Ubink R, Hokfelt T (2000) Expression of neuropeptide $\mathrm{Y}$ in olfactory ensheathing cells during prenatal development. J Comp Neurol 423:13-25.

Valverde F, Santacana M, Heredia M (1992) Formation of an olfactory glomerulus: morphological aspects of development and organization. Neuroscience 49:255-275.

Vassar R, Chao SK, Sitcheran R, Nunez JM, Vosshall LB, Axel R (1994) Topographic organization of sensory projections to the olfactory bulb. Cell 79:981-991.

Vincent AJ, West AK, Chuah MI (2003) Morphological plasticity of olfactory ensheathing cells is regulated by cAMP and endothelin-1. Glia 41:393-403.

Vincent AJ, West AK, Chuah MI (2005a) Morphological and functional plasticity of olfactory ensheathing cells. Journal of Neurocytology 34:65-80.

Vincent AJ, Taylor JM, Choi-Lundberg DL, West AK, Chuah MI (2005b) Genetic expression profile of olfactory ensheathing cells is distinct from that of Schwann cells and astrocytes. Glia 51:132-147. 
Vroemen M, Caioni M, Bogdahn U, Weidner N (2007) Failure of Schwann cells as supporting cells for adult neural progenitor cell grafts in the acutely injured spinal cord. Cell and Tissue Research 327:1-13.

Vukovic J, Ruitenberg MJ, Roet K, Franssen E, Arulpragasam A, Sasaki T, Verhaagen J, Harvey AR, Busfield SJ, Plant GW (2009) The Glycoprotein Fibulin-3 Regulates Morphology and Motility of Olfactory Ensheathing Cells In Vitro. Glia 57:424-443.

Wewetzer K, Kern N, Ebel C, Radtke C, Brandes G (2005) Phagocytosis of O4+ axonal fragments in vitro by p75- neonatal rat olfactory ensheathing cells. Glia 49:577-587.

Whitesides JG, 3rd, LaMantia AS (1996) Differential adhesion and the initial assembly of the mammalian olfactory nerve. J Comp Neurol 373:240-254.

Windus LC, Claxton C, Allen CL, Key B, St John JA (2007) Motile membrane protrusions regulate cell-cell adhesion and migration of olfactory ensheathing glia. Glia 55:1708-1719.

Windus LC, Lineburg KE, Scott SE, Claxton C, Mackay-Sim A, Key B, St John JA (2010) Lamellipodia mediate the heterogeneity of central olfactory ensheathing cell interactions. Cell Mol Life Sci 67:1735-1750.

Windus LC, Chehrehasa F, Lineburg KE, Claxton C, Mackay-Sim A, Key B, St John JA (2011) Stimulation of olfactory ensheathing cell motility enhances olfactory axon growth. Cell Mol Life Sci 68:3233-3247.

Woodhall E, West AK, Chuah MI (2001) Cultured olfactory ensheathing cells express nerve growth factor, brain-derived neurotrophic factor, glia cell line-derived neurotrophic factor and their receptors. Molecular Brain Research 88:203-213.

Woodhall E, West AK, Vickers JC, Chuah MI (2003) Olfactory ensheathing cell phenotype following implantation in the lesioned spinal cord. Cellular and Molecular Life Sciences 60:2241-2253.

Wu J, Sun TS, Ren JX, Wang XZ (2008) Ex vivo non-viral vector-mediated neurotrophin-3 gene transfer to olfactory ensheathing glia: effects on axonal regeneration and functional recovery after implantation in rats with spinal cord injury. Neurosci Bull 24:57-65.

Wu XJ, Bolger WE, Anders JJ (2013) Fibroblasts Isolated from Human Middle Turbinate Mucosa Cause Neural Progenitor Cells to Differentiate into Glial Lineage Cells. PLoS One 8.

Xu XH, Zhou JF, Li TZ, Zhang ZH, Shan L, Xiang ZH, Yu ZW, Zhang WD, He C (2009) Polygalasaponin $G$ promotes neurite outgrowth of cultured neuron on myelin. Neuroscience Letters 460:41-46.

Yamamoto M, Raisman G, Li DQ, Li Y (2009) Transplanted olfactory mucosal cells restore paw reaching function without regeneration of severed corticospinal tract fibres across the lesion. Brain Research 1303:26-31.

Yan H, Bunge MB, Wood PM, Plant GW (2001) Mitogenic response of adult rat olfactory ensheathing glia to four growth factors. Glia 33:334-342.

Zhang SX, Huang FF, Gates M, Holmberg EG (2011) Scar ablation combined with LP/OEC transplantation promotes anatomical recovery and P0-positive myelination in chronically contused spinal cord of rats. Brain Research 1399:1-14.

Ziege S, Baumgartner W, Wewetzer K (2013) Toward defining the regenerative potential of olfactory mucosa: establishment of Schwann cell-free adult canine olfactory ensheathing cell preparations suitable for transplantation. Cell Transplant 22:355-367.

Ziegler MD, Hsu D, Takeoka A, Zhong H, Ramon-Cueto A, Phelps PE, Roy RR, Edgerton VR (2011) Further evidence of olfactory ensheathing glia facilitating axonal regeneration after a complete spinal cord transection. Experimental Neurology 229:109-119. 


\section{Figure legends}

Figure 1. Detrimental effects of secondary spinal cord injury events at the cellular and molecular level. Neurons are shown in green; glia in red. Injury to the spinal cord leads to (1) apoptosis and cell death (neurons and glial cells) with accumulation of cell debris and the generation of a toxic environment due to high extracellular glutamate concentrations and the presence of free radicals; (2) formation of a glial scar which creates a physical barrier consisting of activated astrocytes. The resultant effect is that damaged axons are unable to regenerate and communicate due to presence of inhibitory molecules, loss of myelin and the physical barrier.

Figure 2. Anatomical organisation of the olfactory system. Primary olfactory sensory neurons lie within the olfactory epithelium (OE). Their axons project through the cribriform plate (CP) and enter the olfactory bulb where they terminate in their target glomeruli. OECs within the lamina propria (LP) encase the bundles of numerous different axons as they project to the olfactory bulb. In the outer nerve fibre layer (NFL) of the olfactory bulb, the OECs (red) aid the defasciculation and sorting of the different axons. In the inner layer of the nerve fibre layer the OECs (blue) assist with the refasciculation and targeting of similar axons to their targets. Astrocytes form a barrier around the glomeruli (dashed circles). The olfactory sensory neurons within the OE are subjected to toxic molecules within the inhaled air and pathogens such as bacteria and viruses which can result in the death of the neurons (spotted neurons). OECs phagocytose the debris from the degenerated axons. Stem cells lining the basal layer of the OE replenish the neuron population which project axons through channels maintained by the OECs.

Figure 3. The different populations of glia in the olfactory system. Panels A-F show coronal sections through the olfactory system of a transgenic reporter mouse (OMP-ZsGreen X S100ß- 
DsRed; Windus et al., 2007; Ekberg et al., 2011) that expresses ZsGreen fluorescent protein in olfactory neurons and DsRed fluorescent protein in glia. (A) The primary olfactory neurons (green) within the olfactory epithelium (OE) project axons into the lamina propria (LP) where they coalesce into fascicles wrapped up by OECs (red). Nuclei (blue) are stained with DAPI. (B) Along parts of the septum in the nasal cavity, the axon fascicles of the main olfactory system are adjacent to axon fascicles of the accessory (pheromone) olfactory system. (C) Branches of the trigeminal nerve also innervate the nasal cavity; the trigeminal nerve axons are encased by Schwann cells with the trigeminal nerves running adjacent to the main olfactory nerve fascicles that are encased by OECs (double-headed arrows). (D) The cell bodies of the olfactory glia are mainly restricted to the periphery of the axon fascicles with their processes permeating the central regions of the axon fascicle. (E) Schwann cells of the trigeminal nerve form tube-like encasing of individual axons. (F) In the olfactory bulb, OECs (red) in the nerve fibre layer (NFL) form a barrier with the astrocytes (green; GFAP immunostaining) in the glomerular layer (GL). (G) Schematic of the ensheathment of olfactory axons by OECs. The cell bodies of OECs are largely restricted to the exterior and the processes of the OECs penetrate the internal areas of the nerve bundle where they surround numerous olfactory axons. (H) Schematic of Schwann cell ensheathment of other peripheral nerves in which individual axons are myelinated and encased by Schwann cells. Scale bar is $65 \mu \mathrm{m}$ in A; $50 \mu \mathrm{m}$ in $\mathrm{B} ; 30 \mu \mathrm{m}$ in $\mathrm{C} ; 20 \mu \mathrm{m}$ in $\mathrm{D} ; 15 \mu \mathrm{m}$ in $\mathrm{E} ; 40 \mu \mathrm{m}$ in $\mathrm{F}$.

Figure 4. The potential therapeutic use of OECs for spinal cord repair. OECs (red) can be transplanted with fibroblasts (grey) into the injury site. Strategies that enhance the integration, proliferation and migration of OECs are likely to result in improved axon growth. Targets for improvement can include increasing proliferation of transplanted cells; using fibroblasts to organise alignment and migration of OECs; enhancing how OECs phagocytose cellular debris; optimising the interaction between OECs and activated astrocytes to reduce glial scar formation. 
